\title{
RESENHAS
}

REVIEWS

\section{NOS LIMITES DA VIDA: ABORTO, CLONAGEM HUMANA E EUTANÁSIA SOB A PERSPECTIVA DOS DIREITOS HUMANOS}

\author{
Organização Daniel Sarmento e Flávia Piovesan \\ Rio de Janeiro, Lumen Juris, 2007
}

Clarice Seixas Duarte ${ }^{(*)}$

A obra Nos limites da vida: Aborto, Clonagem humana e Eutanásia sob a perspectiva dos Direitos Humanos ${ }^{(1)}$, coordenada pelo Professor de Direito Constitucional da Universidade Estadual do Rio de Janeiro e Procurador Regional da República, Daniel Sarmento, juntamente com Flávia Piovesan, Professora de Direitos Humanos do Programa de Pós-Graduação da Universidade Pablo de Olavide (Sevilha, Espanha), Procuradora do Estado de São Paulo e membro do CLADEM (Comitê Latino-Americano e do Caribe para a Defesa dos Direitos da Mulher), aborda com seriedade questões extremamente complexas e polêmicas, que envolvem considerações de ordem filosófica, moral e religiosa a respeito do grau de autonomia do indivíduo frente ao Estado na tomada de decisões sobre o sentido da vida e da morte. Diante dos avanços da biotecnologia e da medicina e ao reconhecimento de novos direitos sexuais e reprodutivos, o livro reúne uma coletânea de artigos que vêm contribuir para o aprofundamento do debate sobre disputas que extrapolam o âmbito técnico-jurídico à luz da perspectiva emancipatória dos direitos humanos e dos parâmetros próprios do Estado Democrático de Direito inscrito em nossa Constituição Federal.

(*) Doutora em Filosofia e Teoria Geral do Direito pela Faculdade de Direito da Universidade de São Paulo. Professora do Programa de Pós-Graduação em Direito da Universidade Presbiteriana Mackenzie e Coordenadora do Curso de Especialização em Direitos Humanos da Escola Superior da Procuradoria Geral do Estado de São Paulo. E-mail: <clasduarte@uol.com.br>. Recebido em 04.04.08.

(1) SARMENTO, Daniel; PIOVESAN, Flávia. Nos limites da vida: aborto, clonagem humana e eutanásia sob a perspectiva dos direitos humanos. Rio de Janeiro: Lumen Juris, 2007. 
A escolha dos autores de tratar de temas como o aborto, a clonagem humana e a eutanásia à luz da perspectiva dos direitos humanos é extremamente louvável, pois, possibilitou a abertura do Direito à reflexão sobre questões de cunho moral, seguindo o caminho aberto, pioneiramente, por autores como Ronald Dworkin e Robert Alexy. Essa abordagem permite a superação da tradição juspositivista, calcada na interpretação formalista dos textos legais, independentemente de seu conteúdo axiológico.

A obra divide-se em três partes. A primeira delas trata da temática do aborto e inicia-se com o artigo de Daniel Sarmento, no qual se discute, sob a perspectiva constitucional, a necessidade de revisão do tratamento jurídico dispensado à matéria pelo Código Penal de 1940. O referido diploma legal, em seus arts. 124 e 126, criminaliza a prática do aborto provocado por gestante ou por terceiros com o seu consentimento, salvo nas hipóteses previstas no art. 128 (se não houver outro meio de salvar a vida da gestante ou se a gravidez resultar de estupro). Inspirado pelos princípios de um Estado laico e pluralista inscrito em nossa ordem constitucional, Sarmento defende a necessidade de mudança da legislação sob o argumento de que os direitos do nascituro devem ser ponderados à luz dos direitos fundamentais à saúde, à privacidade, à autonomia reprodutiva e à igualdade da mulher, também protegidos em nosso ordenamento. O desafio deste Estado laico, segundo o autor, é trazer o debate sobre o início da vida para o âmbito da razão pública, independentemente de convicções religiosas ou morais que, não obstante mereçam proteção jurídica, não podem ser impostas a todos.

Já o artigo de Flávia Piovesan, "Direitos Sexuais e Reprodutivos: Aborto Inseguro como violação aos Direitos Humanos", traz as contribuições do arcabouço internacional de proteção dos direitos sexuais e reprodutivos vistos sob a ótica dos direitos humanos, buscando influenciar o debate interno sobre a temática do aborto. A autora nos esclarece que, com fundamento nos direitos à liberdade, à vida e à saúde, o direito internacional vem encorajando os Estados a conferir às mulheres, na qualidade de plenos sujeitos de direito, a partir de suas próprias convicções morais e religiosas, a interrupção da gravidez indesejada, de tal forma a assegurar o seu direito fundamental à dignidade. A autora ressalta, ainda, as trágicas conseqüências decorrentes do abortamento inseguro, praticados, sobretudo, pelas mulheres dos grupos mais vulneráveis da população, o que transforma a questão num problema de saúde pública, e não de repressão penal. Isso porque, sob a perspectiva dos direitos humanos, a realização dos direitos sexuais e reprodutivos demanda uma nova postura do Estado, não apenas no sentido da revisão da legislação existente, como também no sentido de elaborar e implementar políticas públicas para evitar o elevado número de mortes e graves riscos à saúde decorrentes da prática do aborto ilegal. Nesse contexto, a autora defende a tese de que o Estado tem a obrigação de garantir condições legais e seguras para a realização do aborto no sistema nacional de saúde. 
Os artigos de Leila Linhares Barsted, coordenadora do Comitê de Especialistas da OEA para o Monitoramento da Convenção de Belém do Pará e de Silvia Pimentel, vice-presidente do Comitê sobre Eliminação da Discriminação contra a Mulher - CEDAW/ONU e membro do CLADEM Comitê Latino-Americano e do Caribe para a defesa dos direitos da mulher, trazem a perspectiva histórica do movimento de mulheres em prol da descriminalização do aborto, buscando, também com as contribuições do direito internacional, como no artigo de Flávia Piovesan, influenciar a atualização da legislação interna e uma nova postura do Estado diante da questão.

Outro ponto que merece ser destacado diz respeito à atualidade da obra. São apresentados temas que estão na ordem do dia, como o voto proferido pelo Ministro do Superior Tribunal Federal Joaquim Barbosa Gomes no Habeas Corpus n. 84.025/2004, em favor de uma gestante de feto anencefálico que requeria a antecipação terapêutica do parto. Não obstante o julgamento tenha ficado prejudicado, por perda do objeto, face ao nascimento e logo em seguida falecimento do feto, o Ministro divulgou seu voto que, pela relevância de seus argumentos, mereceu ser publicado na obra ora resenhada. Mais uma vez houve a necessidade de ponderação de interesses em colisão. De um lado, os direitos do nascituro que, em razão da anencefalia diagnosticada, teria uma vida extra-uterina inviável e, de outro, a liberdade e autonomia privada da mulher. No caso em tela, o Ministro defendeu que o feto, a partir do momento em que se comprovou a sua inviabilidade, deixou de ser amparado pelo art. 124 do Código Penal, tratando-se de conduta atípica e, portanto, não havendo de se cogitar de ilicitude penal.

O mesmo tema foi abordado no artigo da advogada e pós-graduanda em direitos humanos e relações do trabalho pela Universidade Federal do Rio de Janeiro, Maíra Costa Fernandes. Trazendo contribuições da Medicina acerca do conceito de anencefalia, a autora conclui, na mesma linha do voto do Ministro Joaquim Barbosa Gomes, pela total inadequação da hipótese de interrupção da gravidez de feto anencefálico à norma penal que criminaliza o aborto. Embora esclareça que tal posicionamento seja fruto de uma interpretação conforme à Constituição, a autora acaba recomendando a votação dos projetos de lei já em tramitação na Câmara dos Deputados e no Senado, que inserem mais uma cláusula de exclusão da punibilidade ao art. 128 do Código Penal, sobretudo em face da permanência de decisões calcadas em critérios extremamente formalistas do texto legal.

A segunda parte da obra trata do tema, também extremamente atual, da clonagem humana e da biotecnologia. Inicia-se com o artigo de Heloisa Helena Barboza, professora titular de Direito Civil da Universidade do Estado do Rio de Janeiro. A autora, comentando a Lei n. 11.105/05, a Lei de Biossegurança, alerta para o fato de que a mesma reuniu, num só instrumento, assuntos distintos, orientados por princípios diversos. De um lado, destinou-se, de início, a regulamentar os organismos geneticamente modificados, mas, disciplinou também a pesquisa e terapia com células-tronco obtidas de embriões humanos 
produzidos por fertilização in vitro, inviáveis, ou congelados há mais de três anos. O grande problema no que diz respeito à pesquisa com células-tronco, segundo a autora, reside na destruição do embrião em decorrência da retirada das células-tronco. A autora defende o mérito da referida lei, que autorizou tais pesquisas, ressaltando que os embriões extraídos até o $14^{\circ}$ dia após a fertilização não teriam ainda um sistema nervoso central formado, nem, tampouco, apresentariam nenhum tipo de atividade cerebral. Neste ponto, a autora, ao julgar que não existiria vida humana até esse momento, filia-se à maioria das concepções existentes sobre a matéria. Contudo, para os que entendem que a vida humana inicia-se no momento da concepção, o procedimento representaria um atentado à vida, razão pela qual o art. 5ํㅜ foi alvo da Ação Direta de Inconstitucionalidade - ADI n. 3.510, de 30.5.5. Em julgamento amplamente divulgado pela mídia, o Supremo Tribunal Federal decidiu pela constitucionalidade do referido artigo.

No tocante aos organismos geneticamente modificados, a Lei n. 11.105/ 05 proibiu, de modo genérico, tanto a clonagem reprodutiva como a terapêutica, o que tem gerado muita polêmica. Heloisa Helena Barboza questiona se a proibição da clonagem com fins terapêuticos não colidiria com o direito à saúde, pois a utilização dessa técnica poderia amenizar ou acabar com o sofrimento de muitos pacientes. Indaga, ainda, se a proibição da clonagem reprodutiva não violaria o direito à autonomia reprodutiva assegurado pelo $\S$ $7^{\circ}$ do art. 226 da Constituição Federal. A questão é retomada no artigo dos professores de direito da Pontifícia Universidade Católica de Minas Gerais, Maria de Fátima Freire de Sá e Bruno Torquato de Oliveira. Para os autores, uma coisa é a utilização de embriões excedentes num processo de reprodução assistida; outra, muito diferente, é a utilização da clonagem para produção de células-tronco embrionárias visando atingir finalidades distintas da procriação. O referido artigo questiona se a possibilidade de justificar a formação de embriões para manipulação não permitiria a chamada "instrumentalização do ser humano" que, segundo a conhecida máxima kantiana, deve ser tratado como um "fim em si mesmo".

A polêmica sobre o início da vida volta a aparecer no artigo de Luís Roberto Barroso, constitucionalista da Universidade Estadual do Rio de Janeiro, que a aponta como uma das grandes questões do debate ético contemporâneo. O autor esclarece que, de acordo com a legislação brasileira, a pessoa humana surge apenas com o nascimento com vida. Isso não significa que a lei não resguarde, desde a concepção, os direitos do nascituro, ou seja, o ser humano já concebido, cujo nascimento se espera como fato certo e que deve estar em desenvolvimento no útero da mãe. O autor chama a atenção para o fato de a proteção jurídica ao embrião resultante da feritilização in vitro, ainda não transferido para o útero materno, não se equiparar ao tratamento dispensado nem à pessoa humana, nem ao nascituro. Nesse contexto, as pesquisas com células-tronco embrionárias remanescentes de procedimentos de fertilização in vitro, nas condições postas pela Lei n. 11.105/05, não poderiam 
ensejar violação do direito à vida. Barroso reconhece, ainda, que a referida lei, na medida em que só admite a utilização de embriões inviáveis ou não utilizados no processo de fertilização, protege a sua dignidade.

Finalmente, a terceira parte da obra trata do tema da eutanásia e iniciase com o artigo "A Constituição e o Direito ao Corpo Humano", de Carlos Roberto Siqueira Castro, em que são apresentadas considerações sobre a tutela constitucional do direito à vida, que visa garantir os atributos e condições para o exercício da personalidade humana em sua plenitude, especialmente no que se refere à morte digna, além de um painel histórico sobre diversas experiências e comentários a respeito do tema.

O artigo da antropóloga e doutora em bioética Débora Diniz nos apresenta o caso de um bebê de oito meses portador de uma doença grave e incurável, degenerativa e com curto prognóstico de sobrevida. Segundo a autora, os pais buscaram suporte judicial para garantir que o bebê não fosse compulsoriamente submetido a mecanismos de respiração artificial, caracterizando a chamada "obstinação terapêutica", consistente num excesso de medidas que impõem dor e sofrimento à pessoa doente. Débora comenta, ainda, um outro conceito da bioética, o chamado suicídio assistido, que se distingue da eutanásia pelo fato de o paciente ser apenas assistido para a morte, realizando ele próprio todos os atos que gerem a sua aceleração. Trata-se, em ambos os casos, da discussão a respeito do direito à morte digna, aplicável, conforme nos esclarece a autora, apenas a pessoas doentes e, em especial, àquelas em estado terminal. A chamada "boa morte" seria resultante de uma combinação de princípios morais, religiosos e terapêuticos e um ato de expressão do livre-arbítrio individual, a ser exercido de forma informada e consciente.

Ao longo da obra, os diversos autores mostraram que a concretização dos valores do Estado Democrático de Direito, fundado no princípio da dignidade da pessoa humana, exige a utilização de novos parâmetros jurídicos, especialmente quando se trata da colisão entre diferentes direitos fundamentais constitucionalmente protegidos. O artigo de Ingo Wolfgang Sarlet, Professor Titular de Direito Constitucional da Faculdade de Direito da Pontifícia Universidade Católica do Rio Grande do Sul e juiz de direito em Porto Alegre, ressalta a necessidade de secularização do conceito da dignidade humana, afastando qualquer visão unilateral que possa ditar soluções nas questões suscitadas pela biotecnologia, nos casos de interrupção da gravidez ou eutanásia, moldadas por concepções morais e religiosas particulares.

\section{REFERÊNCIAS BIBLIOGRÁFICAS}

SARMENTO, Daniel; e PIOVESAN, Flávia. Nos limites da vida: aborto, clonagem humana e eutanásia sob a perspectiva dos direitos humanos. Rio de Janeiro: Lumen Juris, 2007. 